CONGENITAL HEART DISEASE

\title{
Clinical impact of first and early second trimester fetal echocardiography on high risk pregnancies
}

\author{
J S Carvalho, G Moscoso, A Tekay, S Campbell, B Thilaganathan, E A Shinebourne
}

Heart 2004;90:921-926. doi: 10.1136/hrt.2003.015065

See end of article for authors' affiliations

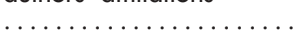

Correspondence to: Dr Julene S Carvalho, Royal Brompton Hospital, Sydney Street, London SW3 6NP, UK:

i.carvalho@

rbh.nthames.nhs.uk

Accepted 16 October 2003

\begin{abstract}
Objective: To evaluate the clinical impact of fetal echocardiography before 16 weeks' gestation on the management of pregnancies with fetuses at risk of congenital heart disease.

Design and setting: Observational study in a fetal medicine unit.

Participants and methods: 222 consecutive women with high risk pregnancies (230 fetuses) underwent transabdominal fetal echocardiography at a median gestation of $14^{+1}$ weeks. For $10 \%$, transvaginal scans were also performed. Criteria for normal scans were normal sequential segmental analysis, symmetrical four chamber view, normal semilunar valves, arterial oufflow tracts, and ductal and aortic arches. Early scans were compared with mid-second trimester fetal echocardiography. Postmortem and postnatal data were added. Adverse pregnancy outcomes were diagnosis of a major cardiac or extracardiac abnormality, chromosomal defects, intrauterine death, or termination of pregnancy.

Results: There were 21 abnormal cardiac scans (9\%): 14 major structural defects (eight isolated, six with chromosomal or extracardiac abnormalities) in pregnancies resulting in three live births, one intrauterine death, and 10 terminated pregnancies. Seven scans showed asymmetry between right and left sided structures (two isolated, five with chromosomal or extracardiac abnormalities); six of the seven pregnancies were terminated. The scans were normal in 199 cases (87\%). Cardiac follow up of 184 of 199 babies (93\%) confirmed situs and connections. One case each of pulmonary stenosis and ventricular septal defect requiring postnatal intervention were diagnosed at later scans. In 28 of 199 (14\%) babies there was a non-cardiac adverse outcome. First examination was not diagnostic for $10(4 \%)$.

Conclusion: Early fetal echocardiography in high risk pregnancies was diagnostic in $96 \%$. Abnormal cardiac scans (isolated in $48 \%$, major structrual defects in $67 \%$ ) led to termination of pregnancy in $76 \%$. Most cardiac scans were normal, allowing family reassurance. The high number of adverse outcomes with normal cardiac anatomy stresses the need for a multidisciplinary approach to early fetal echocardiography.
\end{abstract}

$\mathrm{S}$ ince our report ${ }^{1}$ that fetal cardiac anomalies can be identified by transabdominal echocardiography towards the end of the first trimester, this technique has been applied in other centres where fetal nuchal translucency (NT) is routinely measured. ${ }^{2}$ This echo-free space at the back of the neck is measured at 11-14 weeks' gestation. An increased thickness (typically $>4 \mathrm{~mm}$ ) is strongly associated with abnormal chromosomes, with or without congenital heart disease (CHD). ${ }^{3}$ In a recent study by Huggon and colleagues ${ }^{2}$ cardiac anomalies were confidently identified in 60 of 478 fetuses and suspected in a further 20. Of all their fetuses scanned, $84 \%$ had an increased NT thickness or an abnormal ductus venosus Doppler signal and $39.5 \%$ had abnormal chromosomes (72.9\% of those with cardiac abnormalities). We assessed the impact of early fetal echocardiography on the management of high risk pregnancies, among which the majority of fetuses had normal chromosomes.

\section{METHODS}

\section{Study population}

The population studied consisted of all consecutive patients who underwent detailed fetal echocardiography at a gestational age $\leqslant 16^{+0}$ weeks within our Fetal Medicine Unit by a single experienced operator. Between January 1997 and August 2002, 230 fetuses (222 pregnancies) were studied. The indications for fetal echocardiography were a recognised increased risk of CHD as part of the clinical management of high risk pregnancies (increased NT: 102, family history: 95, abnormal findings during early scan: 6, other indications: 27). Verbal informed consent was obtained in all cases before the ultrasound scan.

Fetal echocardiographic examination

Before each examination the reasons for the cardiac scan were explained and the estimated individual relative risks of CHD were discussed ( $2 \%$ for one and $10 \%$ for two affected children, and $>2 \%$ for increased NT thickness, variable with the specific NT measurement). All patients were informed about the aims of the study. The need for follow up scans and the limitations of first and early second trimester scans related to fetal size (anteroposterior diameter of the fetal chest at 13 weeks of approximately $2.5 \mathrm{~cm}$ ) and resolution obtainable by the ultrasound equipment were pointed out. The sequential segmental approach to diagnosis was used in all cases. ${ }^{5}$ The fetal echocardiogram was targeted to visualise the major cardiac structures and was considered normal if the following were imaged: visceral situs solitus and normal cardiac position; normal and symmetrical four chamber view with two separate atrioventricular valves; normal aortic and pulmonary outflow tracts, including the septoaortic continuity; two great arteries of similar size in a spiral spatial relation (that is, normal crossover with the anterior left sided pulmonary artery crossing from left to right in front of the posterior ascending aorta); and evidence of the ductal and aortic arches. Visualisation of the trabecular

Abbreviations: AVSD, atrioventricular septal defect; $C H D$, congenital heart disease; NT, nuchal translucency; VSD, ventricular septal defect 
part of the interventricular septum was variable. Image optimisation was obtained with the use of colour and power Doppler. Colour flow mapping was routinely used to assess intracardiac and great artery blood flow velocities. Pulsed wave Doppler was not routinely used. All studies were carried out transabdominally. Transvaginal scans were offered if an abnormality was detected or if the information obtained by the transabdominal route was not diagnostic. In addition, all fetuses were assessed by a team specialised in fetal medicine to diagnose or exclude major extracardiac malformations and to measure NT thickness, if appropriate. In all cases where a cardiac abnormality was detected, fetal karyotyping was offered if it had not been carried out previously. In the majority of fetuses assessed, because of an increased NT thickness, karyotyping had already been performed before the detailed cardiac scan.

\section{Follow up and counselling \\ Normal scan group}

Follow up appointments were made for fetal echocardiography at 18-22 weeks. This was used as the ideal for the accuracy of the first trimester scan. Additionally, postnatal information from our own or referring hospitals and postmortem data for cases of either termination of pregnancy or intrauterine death were obtained.

\section{Abnormal scan group}

When a structural cardiac abnormality was detected, the diagnosis and likely postnatal outcome were discussed with the families. Counselling was an integrated approach between the fetal cardiologist and the specialist in fetal medicine. This was particularly important when criteria for normality of the cardiac scan were not met yet no major structural malformation was detected (for example, asymmetry between right and left sided structures; see Results). Clinical geneticists working within the same department provided additional counselling when necessary, for example, when there was a positive family history or a chromosomal anomaly or syndrome. In all cases of termination of pregnancy or intrauterine death, we stressed the importance of confirmatory postmortem examination and its significance for adequate counselling of subsequent pregnancies. Adverse pregnancy outcomes were diagnosis of a major cardiac or extracardiac malformation, a chromosomal abnormality, intrauterine death, or termination of pregnancy.

\section{Postmortem examination}

All specimens were examined with parental consent and in accordance with the guidelines of the Polkinghorne report for the study of fetal tissues. ${ }^{6}$ The protocol used for fixation and for stepwise microdissection of the heart has been published elsewhere. ${ }^{7}$ High flow, low pressure perfusion was used to fix the heart in "end diastole", which was microdissected following the direction of flow. Description of abnormalities followed the sequential segmental approach.

\section{RESULTS}

Fetal echocardiography was performed in 230 fetuses at $\leqslant 16^{+0}$ weeks of gestation. Median gestational age was $14^{+1}$ weeks (range $10^{+1}$ to $16^{+0}$ weeks). In $220(96 \%)$ the scans were diagnostic allowing distinction between 199 normal and 21 abnormal scans. Among the 10 nondiagnostic cases (median gestational age at first examination $11^{+6}$ weeks, range $10^{+1}$ to $13^{+6}$ ), seven fetuses were shown to be normal on subsequent scans, two pregnancies were terminated (trisomy 18), and one fetus died after laser treatment for twin to twin transfusion syndrome before a repeat scan could be performed (first scan at $10^{+1}$ weeks). Transvaginal scans were carried out in 24 cases in addition to the transabdominal route. This combined approach was helpful in three of 10 abnormal cases and in 12 of 14 normal scans.

\section{Normal scans}

In 199 cases, criteria for a normal early scan were met and the families were reassured that no major structural cardiac abnormality was detected (fig 1). In 15 the early findings could not be confirmed: five families opted to terminate the pregnancy for non-cardiac fetal abnormalities (four abnormal chromosomes), four fetuses died spontaneously before a second cardiac scan (no postmortem examination), and six were lost to follow up. Of the remaining 184 scans, normal situs and cardiac connections were subsequently confirmed in all. In seven, normality was confirmed at postmortem examination (six terminated pregnancies due to extracardiac and chromosomal abnormalities and one intrauterine death before follow up scan). One fetus, considered to have a
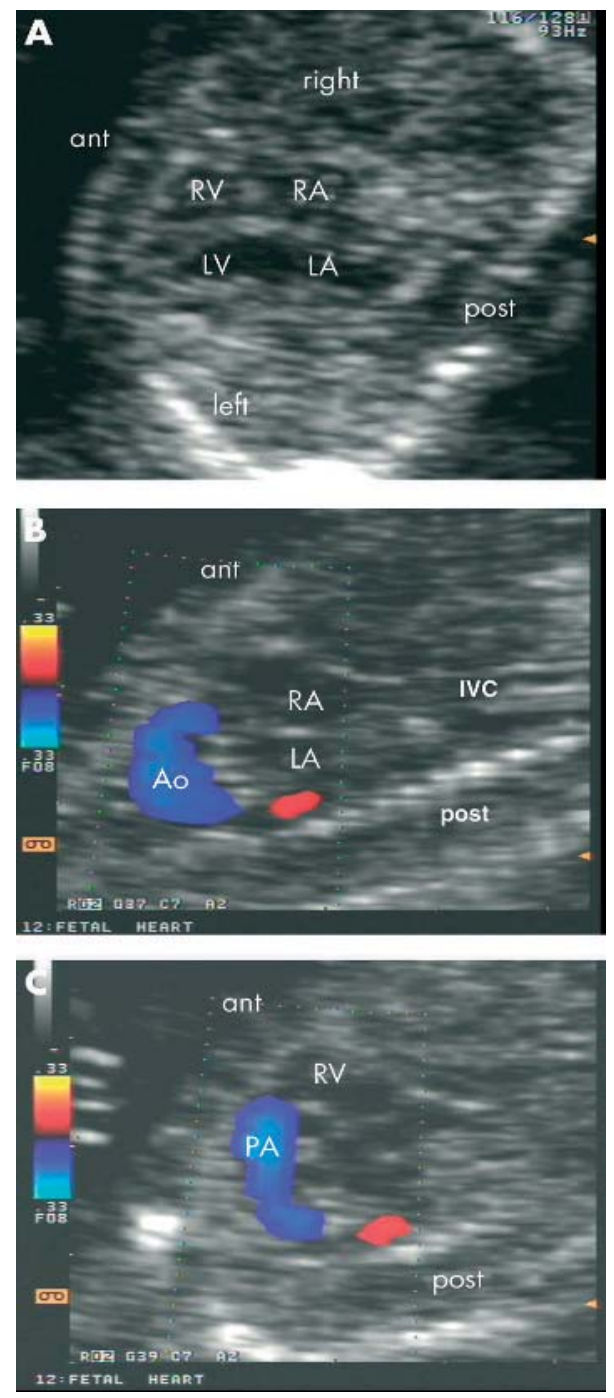

Figure 1 Normal transabdominal fetal echocardiogram from a 13 week fetus. (A) Transverse section of the fetal chest shows a normal four chamber view. Longitudinal sections of the fetus show normal (B) aortic and (C) ductal arches. ant, anterior; Ao, aorta; IVC, inferior vena cava; LA, left atrium; LV, left ventricle; PA, pulmonary artery; post, posterior; $R A$, right atrium; $R V$, right ventricle. 



normal early scan at $14^{+6}$ weeks, had mild valvar pulmonary stenosis on follow up at $21^{+6}$ weeks, which progressed throughout gestation and required balloon dilatation in the early neonatal period. Retrospective review of the videotape images suggested mildly abnormal movement of the pulmonary valve leaflets at $14^{+6}$ weeks. One fetus was shown to have a large ventricular septal defect (VSD) on follow up. Three other fetuses were found to have a small VSD on the
20-22 week scan. Two VSDs closed spontaneously before delivery and in one case a tiny mid-muscular defect was still present in the neonate. Six liveborn babies had chromosomal defects.

\section{Abnormal scans}

The initial scan was abnormal in 21 cases. Twelve cases showed a major structural malformation of the heart (fig 2).

\begin{tabular}{|c|c|c|c|c|c|c|}
\hline Patient & Indication & $\begin{array}{l}\text { GA } \\
\text { (weeks }{ }^{\text {tdays) }}\end{array}$ & Cardiac findings & $\begin{array}{l}\text { Other ultrasound } \\
\text { findings }\end{array}$ & Karyotype & Outcome \\
\hline 1 & $\begin{array}{l}\text { Abnormal four } \\
\text { chamber scan }\end{array}$ & $12^{+1}$ & $\begin{array}{l}\text { Left isomerism, AVSD, } \\
\text { two great arteries }\end{array}$ & Encephalocoele & Normal & $\begin{array}{l}\text { TOP at } 14^{+1} \text { weeks, postmortem } \\
\text { confirmation; additional } \\
\text { interrupted aortic arch }\end{array}$ \\
\hline 2 & $\begin{array}{l}\text { Increased NT, } \\
\text { mosaicism for T21 }\end{array}$ & $14^{+4}$ & $\begin{array}{l}\text { Possible AVSD (no TV } \\
\text { done) }\end{array}$ & Nil & $\begin{array}{l}\text { T21 } \\
\text { (mosaicism) }\end{array}$ & $\begin{array}{l}\text { TOP at } 14^{+6} \text { weeks, postmortem } \\
\text { AVSD }\end{array}$ \\
\hline 3 & Increased NT, T21 & $15^{+5}$ & AVSD & Nil & $\mathrm{T} 21$ & $\begin{array}{l}\text { Intrauterine death at } 17^{+6} \text { weeks, } \\
\text { no postmortem examination }\end{array}$ \\
\hline 4 & Increased NT & $12^{+6}$ & $\begin{array}{l}\text { Hypoplastic left heart } \\
\text { syndrome }\end{array}$ & Hydropic fetus & Normal & $\begin{array}{l}\text { TOP at } 13 \text { weeks, postmortem } \\
\text { confirmation }\end{array}$ \\
\hline 5 & Bradycardia & $12^{+5}$ & $\begin{array}{l}\text { Left isomerism, common } \\
\text { atrium, AVSD, common valve, } \\
\text { DORV (Ao <PA), heart block } \\
\text { (rate } 60 \text { beats } / \mathrm{min} \text { ) }\end{array}$ & Nil, normal NT & Normal & $\begin{array}{l}\text { TOP at } 13^{+3} \text { weeks, postmortem } \\
\text { confirmation; additional severe } \\
\text { distal arch hypoplasia }\end{array}$ \\
\hline 6 & Previous T21, AVSD & $13^{+2}$ & Possible VSD (no TV done) & $\begin{array}{l}\text { Increased NT, } \\
\text { hydropic fetus }\end{array}$ & T21 & $\begin{array}{l}\text { TOP at } 13^{+6} \text { weeks, postmortem } \\
\text { perimembranous outlet VSD }\end{array}$ \\
\hline 7 & Increased NT, T21 & $14^{+6}$ & AVSD, pulmonary atresia & Nil & T21 & $\begin{array}{l}\text { TOP at } 16^{+4} \text { weeks, no } \\
\text { postmortem examination }\end{array}$ \\
\hline 8 & Increased NT & $13^{+3}$ & Complete transposition & Nil & Normal & $\begin{array}{l}\text { Live birth, successful neonatal } \\
\text { arterial switch procedure }\end{array}$ \\
\hline 9 & Increased NT & $14^{+0}$ & $\begin{array}{l}\text { Mitral atresia, VSD, } \\
\text { pulmonary arresia }\end{array}$ & Nil & Normal & $\begin{array}{l}\text { TOP at } 14^{+3} \text { weeks, postmortem } \\
\text { confirmation }\end{array}$ \\
\hline 10 & $\begin{array}{l}\text { Increased NT, } \\
\text { bradycardia }\end{array}$ & $11^{+3}$ & $\begin{array}{l}\text { Left isomerism, AVSD, } \\
\text { heart block }\end{array}$ & Nil & Not done & $\begin{array}{l}\text { TOP at } 12^{+5} \text { weeks, no } \\
\text { postmortem examination }\end{array}$ \\
\hline 11 & Family history & $14^{+5}$ & $\begin{array}{l}\text { Small mitral valve, left } \\
\text { ventricle, pulmonary atresia }\end{array}$ & Nil & Not done & $\begin{array}{l}\text { TOP at } 14 \text { weeks, no postmortem } \\
\text { examination }\end{array}$ \\
\hline 12 & Increased NT & $13^{+4}$ & Tricuspid atresia & Nil & Normal & $\begin{array}{l}\text { TOP }<16 \text { weeks, no postmortem } \\
\text { examination }\end{array}$ \\
\hline 13 & $\begin{array}{l}\text { Increased NT, } \\
\text { pericardial effusion }\end{array}$ & $14^{+4}$ & $\begin{array}{l}\text { Large cardiac diverticulum, } \\
\text { pericardial effusion }\end{array}$ & Hydrops & Normal & Live birth, small RV diverticulum \\
\hline 14 & Increased NT & $15^{+5}$ & AVSD & $\mathrm{Nil}$ & $\mathrm{T} 21$ & Live birth, successful AVSD repair \\
\hline
\end{tabular}

Ao, aorta; $\mathrm{AVSD}$, atrioventricular septal defect; $\mathrm{DORV}$, double outlet right ventricle; $\mathrm{GA}$, gestational age; $\mathrm{NT}$, nuchal translucency; $\mathrm{PA}$, pulmonary artery; $\mathrm{RV}$, right ventricular; T21, trisomy 21 ; TOP, termination of pregnancy; TV, transvaginal scan; VSD, ventricular septal defect. 
Table 2 Abnormal cardiac scans showing asymmetry between right and left sided structures

\begin{tabular}{|c|c|c|c|c|c|c|}
\hline Patient & Indication & $\begin{array}{l}\text { GA } \\
\text { (weeks }^{+ \text {days })}\end{array}$ & Cardiac findings & Other ultrasound findings & Karyotype & Outcome \\
\hline 1 & Increased NT & $13^{+0}$ & Asymmetry RV/LV & $\begin{array}{l}\text { Increased NT of } 7 \mathrm{~mm} \text {, } \\
\text { no other findings }\end{array}$ & Normal & $\begin{array}{l}\text { Planned for serial scans; TOP at } 13 \\
\text { weeks, postmortem severely } \\
\text { narrowed aortic isthmus }(<300 \mu \mathrm{m}) \text {. }\end{array}$ \\
\hline 2. & $\begin{array}{l}\text { Family history } \\
\text { congenital heart } \\
\text { disease }(\times 2)\end{array}$ & $13^{+1}$ & $\begin{array}{l}\text { Asymmetry RV/LV and } \\
\text { Ao/PA, right sided heart }\end{array}$ & $\begin{array}{l}\text { Diaphragmatic hernia } \\
\text { suspected at } 15 \text { weeks; } \\
\text { severe diaphragmatic } \\
\text { hernia, left heart } \\
\text { hypoplasia at } 19 \text { weeks }\end{array}$ & Normal & $\begin{array}{l}\text { TOP at } 21^{+3} \text { weeks, postmortem } \\
\text { large diaphragmatic hernia with } \\
\text { severe lung hypoplasia, hypoplasia } \\
\text { of the LV and severely hypoplastic } \\
\text { aortic arch }\end{array}$ \\
\hline 3 & $\begin{array}{l}\text { Increased NT, } \\
\text { unbalanced } \\
\text { translocation }\end{array}$ & $16^{+0}$ & Asymmetry RV/LV & $\begin{array}{l}\text { Progressive left ventricular } \\
\text { outflow obstruction on } \\
\text { subsequent scans }\end{array}$ & $\begin{array}{l}\text { Unbalanced } \\
\text { translocation } \\
(7 / 15)\end{array}$ & $\begin{array}{l}\text { TOP at } 23^{+6} \text { weeks, postmortem } \\
\text { severe hypoplasia of LV and aortic } \\
\text { arch }\end{array}$ \\
\hline 4 & Increased NT & $14^{+1}$ & $\begin{array}{l}\text { Asymmetry } \mathrm{RV} / \mathrm{LV} \text {, } \\
\text { right sided heart }\end{array}$ & $\begin{array}{l}\text { Limb abnormality, } \\
\text { suspected diaphragmatic } \\
\text { hernia }\end{array}$ & Normal & $\begin{array}{l}\text { TOP at } 14^{+2} \text { weeks, no postmortem } \\
\text { examination }\end{array}$ \\
\hline 5 & Increased NT & $13^{+1}$ & Small aortic isthmus & $\begin{array}{l}\text { Increased NT of } 7.9 \mathrm{~mm} \text {; } \\
\text { no other findings }\end{array}$ & Normal & $\begin{array}{l}\text { Planned for serial scans; TOP at } 13 \\
\text { weeks, no postmortem examination }\end{array}$ \\
\hline 6 & Increased NT & $13^{+3}$ & $\begin{array}{l}\text { Asymmetry RV/LV, distal } \\
\text { aortic arch not seen }\end{array}$ & Cystic hygroma & $45 \times 0$ & $\begin{array}{l}\text { TOP at } 14^{+0} \text { weeks, postmortem } \\
\text { severely narrowed aortic arch and } \\
\text { isthmus }\end{array}$ \\
\hline 7 & Exomphalos & $14^{+2}$ & $\begin{array}{l}\text { Asymmetry RV/LV and } \\
\text { Ao/PA }\end{array}$ & Exomphalos & Normal & $\begin{array}{l}\text { Live birth, successful repair of } \\
\text { coarctation and exomphalos }\end{array}$ \\
\hline
\end{tabular}

In two with concordant atrioventricular and ventriculoarterial connections, septal defects were suspected (table 1). Scans for the other seven fetuses showed asymmetry between the right and left sided cardiac structures, the left being smaller (table 2).

Of the 14 fetuses with structural cardiac abnormalities, five had trisomy 21 . Two of these families chose termination of pregnancy mainly because of the chromosomal abnormality. In both, NT was increased and the transabdominal scans indicated a complete atrioventricular septal defect (AVSD) in one and a VSD in the other. Transvaginal scans were not carried out, as the families opted for fetal karyotyping before further investigations. Postmortem examination confirmed the ultrasound findings in both. Another fetus with trisomy 21 and an AVSD died spontaneously (no postmortem examination was done). For the remaining fetus with this chromosomal abnormality, the family decided to terminate the pregnancy only after a complete AVSD and pulmonary atresia were diagnosed at $14^{+6}$ weeks. In one case with a complete AVSD (no invasive tests), trisomy 21 was confirmed at birth. Of the remaining nine fetuses, identification of a major cardiac defect was the main reason for or contributed to a decision to terminate the pregnancy in seven cases (four consented to postmortem examination, where the cardiac diagnoses were confirmed). Two families continued with the pregnancy after the diagnoses of complete transposition of
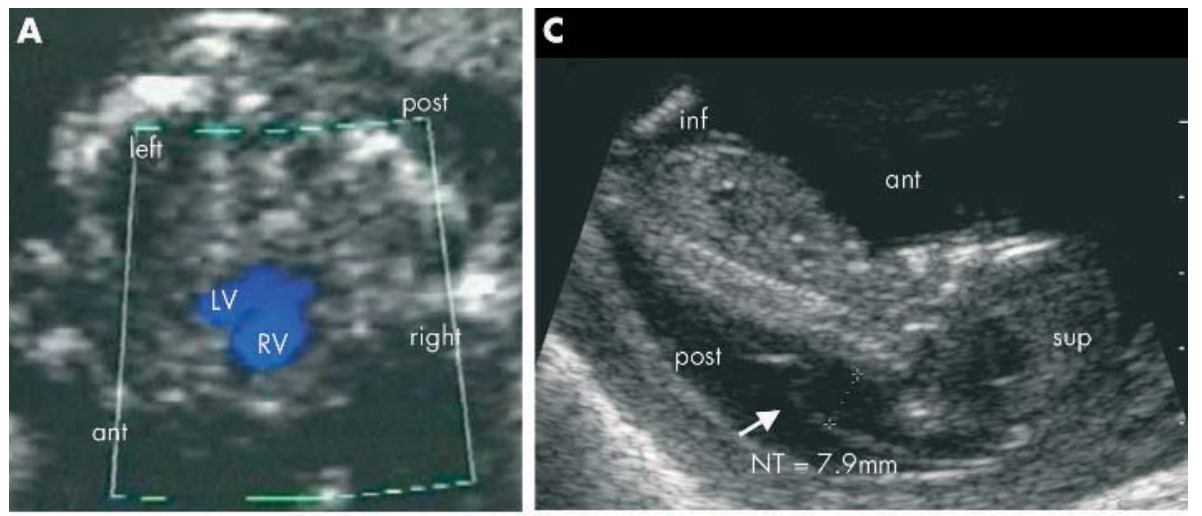

Figure 3 (A, B) Transabdominal views of a fetus at 13 weeks of gestation with diaphragmatic hernia. (A) Transverse section through the fetal thorax shows ventricular asymmetry $(\mathrm{LV}<\mathrm{RV})$ and heart to the right side. (B) Transverse upper mediastinal view shows a narrow transverse aortic arch (arrow). (C, D) Transabdominal views of a fetus at 13 weeks of gestation with (C) greatly increased nuchal translucency (NT, arrow). (D) Aortic arch imaged on power Doppler shows narrowing at the aortic isthmus (arrow). inf, inferior; sup, superior.
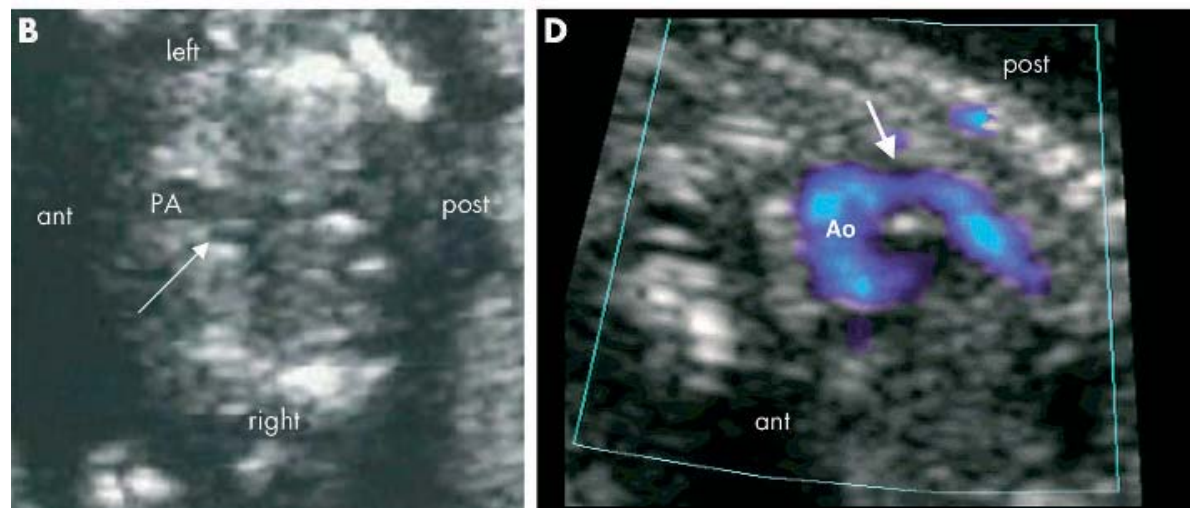
the great arteries at $13^{+3}$ weeks in one (fig 2) and a large cardiac diverticulum with pericardial effusion in another $\left(14^{+4}\right.$ weeks) (table 1$)$.

In seven fetuses dissimilar sizes of the ventricles on the four chamber view, of the great vessels, or both were observed (fig 3). In five, the indication for fetal echocardiography was increased NT or cystic hygroma on previous scans. Two had chromosomal abnormalities (one with Turner's syndrome, one with unbalanced translocation, both with increased NT). Of the five fetuses with normal chromosomes, two had a right sided heart and diaphragmatic hernia (confirmed at postmortem examination in one with normal NT; no postmortem examination was done in another with increased NT and associated limb abnormality), two had greatly increased NT but no additional abnormalities on the early scan, and one had an associated exomphalos. Six families decided to terminate the pregnancy. In two cases this decision was only made after follow up scans in midgestation, which showed major hypoplasia of the left side of the heart (one with diaphragmatic hernia, one with unbalanced translocation). Four families consented to a postmortem examination, which showed aortic or left ventricular hypoplasia in all (table 2). Two families declined postmortem examination. In the only ongoing pregnancy in this group, the fetus was later shown to have coarctation of the aorta (table 2).

Of the 21 abnormal fetuses, the ultrasound findings were confirmed in 14 (10 postmortem examinations, four postnatal scans). The remaining seven fetuses were not examined after death. Overall, the number of fetal pathologies encountered among the 230 fetuses studied was high. There were 23 with chromosomal abnormalities (10\%) in the whole group, which included seven of the 21 (33\%) fetuses with cardiac anomalies. Four with an AVSD and one with a VSD had trisomy 21. Of the two with a hypoplastic aortic arch, one had Turner's syndrome and one had an unbalanced translocation. The remaining $14(67 \%)$ patients with a cardiac abnormality had a normal karyotype. There were 32 terminated pregnancies (14\%), nine intrauterine deaths (4\%), 23 chromosomal abnormalities (10\%), and 16 euploid fetuses with major extracardiac abnormalities (7\%).

\section{DISCUSSION}

Fetal echocardiography carried out at $\leqslant 16^{+0}$ weeks on fetuses at risk of CHD allowed distinction between normal and abnormal cardiac appearances in the majority of cases $(96 \%)$. There was a relatively high number of cardiac abnormalities (9\%) but early reassurance was possible for most families. For those with an abnormal early scan, the identification of cardiac defects, in isolation or associated with other fetal abnormalities, contributed to a very high rate of termination of pregnancy (76\%). Among 199 fetuses considered to have a normal heart at the time of the first examination, 29 (15\%) were subsequently shown to have an adverse outcome related to non-cardiac causes, reflecting the high risk of the population studied.

Most CHD encountered in our study were seen in fetuses who had increased NT thickness (16 of 21 cases). Measurement of NT in the first trimester is a non-invasive way of assessing risks of chromosomal abnormalities. ${ }^{8}$ It is well established in a number of centres in the $\mathrm{UK}^{9}$ and elsewhere. For chromosomally normal fetuses with increased NT, the risk of CHD increases with NT thickness. ${ }^{40-12}$ Mavrides and colleagues ${ }^{11}$ have shown that in an unselected population, the risk for major CHD increases from 3.1 cases in 1000 (normal NT thickness $<2.5 \mathrm{~mm}$ ) to 50 abnormalities in 1000 ( $5 \%$ risk) if NT is above the 99th centile for crown to rump length ( $\mathrm{NT} \geqslant 3.5 \mathrm{~mm}$ ). The latter is similar to the study of Ghi and colleagues, ${ }^{12}$ who reported a $7 \%$ incidence of major CHD in chromosomally normal fetuses with NT $>3.5 \mathrm{~mm}$.

When the criteria for a normal cardiac scan were met, families could be reassured early during their pregnancy, This, together with extracardiac fetal assessment and exclusion of other major fetal abnormalities, was important for continuation of pregnancy. Follow up data showed no major cardiac defect in all but two fetuses, one of whom had a progressive lesion requiring neonatal intervention and the other a large VSD. The former case confirmed observations made by others regarding the progression of certain lesions during pregnancy ${ }^{13}$ but accounted for $<1 \%$ of all normal early scans. This case does, however, stress the need for later follow up both to ensure continuing adequate growth of all cardiac structures and to confirm the early ultrasound findings of normality. Mid-second trimester scans would provide better definition of the septal structures and ascertainment of normal pulmonary venous connections.

That a complex structural malformation of the heart can be diagnosed accurately in early pregnancy has been confirmed in all cases where the heart was available for postmortem examination. The identification of such defects inevitably contributes to a family's decision to interrupt the pregnancy wherever this is a legal option. Particularly if there are no other major fetal abnormalities, the need for accuracy in the cardiac diagnosis is imperative. To confirm this, as well as to counsel families adequately for subsequent pregnancies, a request for a postmortem examination should be mandatory. High quality pathological assessment of such small hearts, however, is not widely available. This poses difficulties that will need to be addressed by those undertaking early fetal echocardiography.

A group of fetuses presented with disproportion between the right and left sided structures, the natural history of which is still unknown. ${ }^{14}$ In this group, the early scan raised the possibility of $\mathrm{CHD}$, which may develop further as pregnancy progresses, yet it provided neither the reassurance of a normal scan nor sufficient information to allow families to decide to interrupt the pregnancy because of a fetal cardiac abnormality alone. In our series, five of seven fetuses that presented with asymmetry between right and left sided structures had greatly increased NT, an associated chromosomal abnormality, or both. Two had diaphragmatic hernia, one with increased NT and one with asymmetry but a normal karyotype and normal NT measurement. In one case, later scans were indicative of coarctation of the aorta. When there is ventricular disproportion, the early scan may or may not allow sufficient delineation of the aortic arch to show associated narrowing of the aortic isthmus. This may only be documented with postmortem examination. Hyett and colleagues $^{3}$ showed that increased NT and isthmal hypoplasia are associated in early pregnancy but, in the absence of other cardiac abnormalities, it is not possible to predict what the postnatal findings will be if a pregnancy continues.

Imaging the fetal heart in the late first and early second trimester of pregnancy is technically more demanding than in mid-gestation because of the relatively smaller size of the fetus and cardiac structures (the semilunar valves are about $1.2 \mathrm{~mm}$ at 13 weeks). The quality of images also depends on maternal size and fetal position. The use of colour flow mapping and power Doppler provides useful additional information that allows pattern recognition of the cardiac connections and valve function. The value of this additional information cannot be underestimated.

Our study confirms the feasibility and utility of early cardiac scans for high risk pregnancies, particularly regarding early reassurance. It stresses the need for a combined fetal medicine approach to include cardiac and extracardiac fetal 
assessment, particularly if NT is increased, whether or not the fetal karyotype is normal.

\section{ACKNOWLEDGEMENTS}

JSC was partially funded by the Hyman Marks Paediatric Research Fund, Royal Brompton Hospital.

\section{Authors' affiliations}

J S Carvalho*, Brompton Fetal Cardiology, Royal Brompton Hospital, London, UK

E A Shinebourne, Brompton Paediatric Cardiology, Royal Brompton Hospital

G Moscoso, A Tekay, S Campbell, B Thilaganathan, Fetal Medicine Unit, St George's Hospital, London, UK

*Also Fetal Medicine Unit, St George's Hospital

\section{REFERENCES}

1 Carvalho JS, Moscoso G, Ville Y. First-trimester transabdominal fetal echocardiography. Lancet 1998;351:1023-7.

2 Huggon IC, Ghi T, Cook AC, et al. Fetal cardiac abnormalities identified prior to 14 weeks gestation. Ultrasound Obstet Gynecol 2002;20:22-9.

3 Hyett J, Moscoso G, Nicolaides K. Increased nuchal translucency in trisomy 21 fetuses: relationship to narrowing of the aortic isthmus. Hum Reprod 1995; 10:3049-51.
4 Hyett J, Perdu M, Sharland G, et al. Using fetal nuchal translucency to screen for major congenital cardiac defects at 10-14 weeks of gestation: population based cohort study. BMJ 1999;318:81-5.

5 Shinebourne EA, Macartney FJ, Anderson RH. Sequential chamber localization: a logical approach to diagnosis in congenital heart disease. $\mathrm{Br}$ Heart J 1976:38:327-40.

6 Anon. Review of the guidance on the research use of fetuses and fetal material (Polkinghorne report). London: Her Majesty's Stationery Office, 1989.

7 Moscoso G, Pexieder T. Variations in microscopic anatomy and ultrastructure of human embryonic hearts subjected to three different modes of fixation. Pathol Res Pract 1990;186:768-74.

8 Nicolaides KH, Azar G, Byrne D, et al. Fetal nuchal translucency: ultrasound screening for chromosomal defects in first trimester of pregnancy. BMJ 1992;304:867-9.

9 Snijders RJ, Noble P, Sebire N, et al. UK multicentre project on assessment of risk of trisomy 21 by maternal age and fetal nuchal-translucency thickness at 10-14 weeks of gestation. Lancet 1998;352:343-6.

10 Hyett JA, Perdu M, Sharland GK, et al. Increased nuchal translucency at 1014 weeks of gestation as a marker for major cardiac defects. Ultrasound Obstet Gynecol 1997; 10:242-6.

11 Mavrides E, Cobian-Sanchez F, Tekay A, et al. Limitations of using firsttrimester nuchal translucency measurement in routine screening for major congenital heart defects. Ultrasound Obstet Gynecol 2001;17:106-10.

12 Ghi T, Huggon IC, Zosmer N, et al. Incidence of major structural heart defects associated with increased nuchal translucency but normal karyotype. Ultrasound Obstet Gynecol 2001;18:610-4.

13 Yagel S, Weissman A, Rotstein Z, et al. Congenital heart defects: natural course and in utero development. Circulation 1997;96:550-5.

14 Bronshtein M, Zimmer EZ, Gerlis LM, et al. Early ultrasound diagnosis of fetal small left ventricle with a normal proximal outlet tract: a medical dilemma. Prenat Diagn 1997; 17:249-53

\section{IMAGES IN CARDIOLOGY}

Optimal management of left ventricular aneurysms after ventricular septal defect closure

A n asymptomatic 29 year old woman with left ventricular aneurysms was referred to our institution for surgical treatment. At the age of 1 year she had undergone closure of a membranous ventricular septal defect at another institution. The defect was closed with a synthetic patch through a combined right transatrialtransventricular approach.

Four years later, during hospitalisation for pneumonia, a chest $x$ ray revealed cardiomegaly (cardiothoracic index 0.65). Echocardiography and subsequent cardiac angiography revealed the presence of two aneurysms on the left ventricle, one on the anterior wall and another on the posterior wall.

Two dimensional echocardiography showed a dyskinetic wall motion at the level of the aneurysms, while left ventricular function was within normal limits (ejection fraction $48 \%$ ).

A multislice computed tomographic (CT) scan of the heart with three dimensional reconstruction allowed us to define the external anatomy of the two aneurysms and their relation with the left anterior descending and posterior descending coronary arteries (panels A-C: A, anterior aneurysm; LAD, left anterior descending coronary artery; LV,
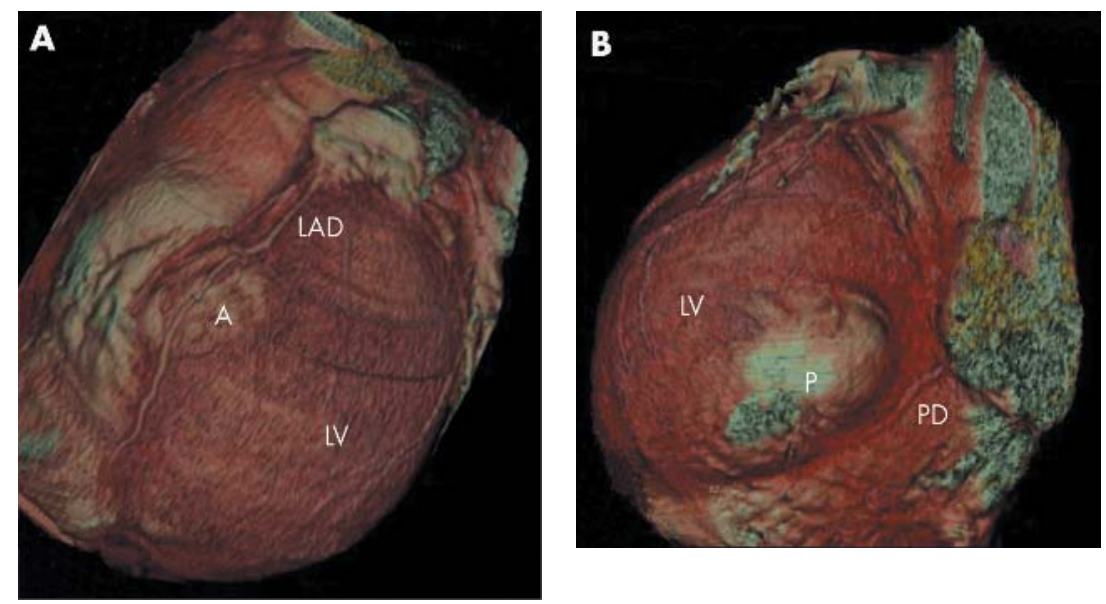

left ventricle; P, posterior aneurysm; PD, posterior descending coronary artery).

Multislice CT scanning of the heart with three dimensional reconstruction represents a reliable non-invasive method to assess the size and landmarks of left ventricular aneurysms and their relation to other heart structures.

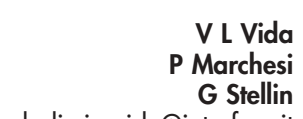
vladimirovida@interfree.it

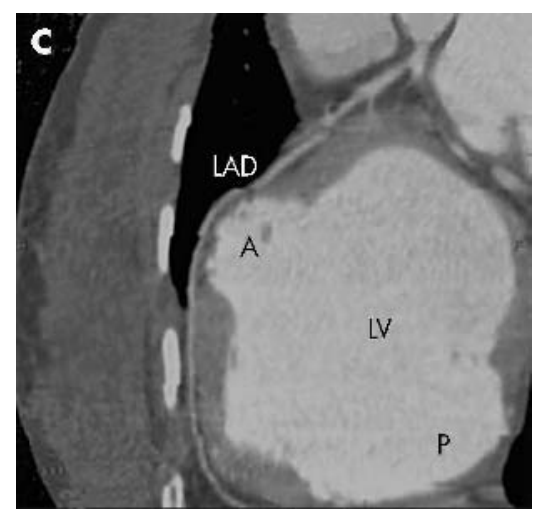

